\title{
Destruction Law of Borehole Surrounding Rock of Granite under Thermo-Hydro-Mechanical Coupling
}

\author{
Jinwen Wu $\mathbb{D}^{1},{ }^{1}$ Zijun Feng $\mathbb{D}^{2,3}$ Shuping Chen ${ }^{2}{ }^{1},{ }^{1}$ and Wenmei Han $\mathbb{D}^{1}$ \\ ${ }^{1}$ School of Science, North University of China, Taiyuan, Shanxi 030051, China \\ ${ }^{2}$ College of Mining Technology, Taiyuan University of Technology, Taiyuan, Shanxi 030024, China \\ ${ }^{3}$ Key Laboratory of In-Situ Property-Improving Mining of Ministry of Education, Taiyuan University of Technology, Taiyuan, \\ Shanxi 030024, China \\ Correspondence should be addressed to Jinwen Wu; wujinwen1982@163.com and Zijun Feng; fengzijun@tyut.edu.cn
}

Received 10 November 2020; Revised 11 December 2020; Accepted 15 December 2020; Published 30 December 2020

Academic Editor: Yanlin Zhao

Copyright (c) 2020 Jinwen Wu et al. This is an open access article distributed under the Creative Commons Attribution License, which permits unrestricted use, distribution, and reproduction in any medium, provided the original work is properly cited.

\begin{abstract}
The destruction of the rock that surrounds boreholes under thermo-hydro-mechanical coupling is an important factor for borehole stability in hot dry rock (HDR) geothermal energy extraction. Failure experiments for granite under triaxial stress $\left(\sigma_{1}>\sigma_{2}>\sigma_{3}\right)$ were conducted as $500^{\circ} \mathrm{C}$ superheated steam was transported through the borehole. High-temperature steam leads to large thermal cracks in the surrounding rock, which are randomly distributed around the borehole and gradually expand outwards. The randomly distributed thermally induced microcracks increase the complexity of the initial fracture morphology around the borehole and contribute to the appearance of multiple branch fractures. Fracture development is negligibly affected by ground stresses during the initial stages. However, fractures are deflected towards the maximum horizontal principal stress under ground stresses during later periods. During fracture propagation, high-temperature steam more easily penetrates the rock because its viscosity is lower than water. Towards the end of the crack expansion, the steam loses heat and liquefies, which increases the elongation resistance, and results in the arrest and intermittent expansion of the cracks.
\end{abstract}

\section{Introduction}

The geothermal energy of hot dry rock (HDR) is an undeveloped, safe, and renewable energy that is abundant all around the world $[1,2]$. China has a large number of geothermal resources, with developmental potential, which are distributed primarily in Tengchong in the Yunnan province, Qiongbei in the Hainan province, Changbaishan in the Jilin province, Wudalianchi in the Heilongjiang province, and Yangbajing in Tibet [3-5].

From 1973 to 1982, a group of scientists from the USA, Japan, and Germany carried out successful HDR geothermal resource extraction tests in Mount Fenton, New Mexico [1, 2, 6 , 7]. The USA built the first HDR geothermal power plant in 1981. In the following decades, France, Germany, Japan, and other countries conducted experiments to extract HDR geothermal resources, and a series of research achievements were obtained $[1,2,8-13]$.
The geothermal energy resources of HDR are mainly stored in granite strata. Injection and production wells are needed in the granite to develop geothermal energy, where artificial reservoirs are built using hydrofracturing [14]. High temperatures trigger thermal cracking in the rock and induce changes in its internal structure. The physical and mechanical properties of rocks near wellbores change with higher temperatures, for example, decreased elastic modulus, a drop in mechanical strength, and increased permeability [15-18]. In addition, thermal stresses accelerate the crushing of the rock that surrounds the wellbore, which significantly reduces the drilling stability [19]. The failure, deformation of the neck, instability, and collapse of the surrounding rock cause a substantial increase in the drilling and maintenance cost of wellbores. Most enhanced geothermal system (EGS) wells are vertical and located in a normal or strike-slip faulting regime. Under these conditions, hydraulic fractures would be expected to form axially along the wellbore. However, 
wellbore observations from EGS projects indicate that flows have typically been localized at discrete zones along the wellbore and correlate with the locations of preexisting fractures. This may be caused by mechanical instabilities in the rock matrix during stimulation [13]. Therefore, the destruction and stability of the granite that surrounds boreholes under thermo-hydro-mechanical coupling are essential factors that restrict the efficient extraction of HDR geothermal energy.

Borehole damage is caused by stress concentration at the cross-section of the wellbore [20]. At room temperature, rock cut from the original location during the drilling process leads to a loss of support in the rock around the borehole. Intragranular and transgranular microcrack expansions are generated in the granite around boreholes, which can cause the exfoliation of local minerals and lead to borehole failure [20]. Subjected to continuous loads such as hydraulic pressure and stress, the rock crack rheological fracture can take place as time goes, which results in reduced stability of the borehole surrounding rock mass [21]. In high-temperature drilling processes, mud circulation is used to cool the bit. During the exploitation of HDR geothermal energy, water is injected into the reservoir for heat exchange to rapidly cool the hot rock mass close to the injection wells while the peripheral rock mass undergoes slow cooling. The sudden decrease of temperature around the wellbore, i.e., thermal shock, causes thermal cracking. Normally, the degradation of the rock mechanical properties under thermal shock is greater than that under slow cooling [22]. Hence, during the extraction of HDR geothermal energy, the boreholes are under the conditions of high temperature and pressure, which increases the complexity of the destruction law of the granite surrounding the borehole.

Zhao [23] simulated the drilling process at different temperatures at a $4000 \mathrm{~m}$ depth $(100 \mathrm{MPa})$ in his doctoral thesis. $\mathrm{He}$ found that there were no obvious cracks around the borehole at $150^{\circ} \mathrm{C}$. When the temperature increased to $300^{\circ} \mathrm{C}$, several radial cracks appeared around the borehole and rock particles on the inner wall of the borehole fell off. At $500^{\circ} \mathrm{C}$, the radial crack width around the borehole increased significantly, and a severe fracture zone appeared in the borehole. Zhao et al. [24] performed stability experiments of granite drilling under high temperature and pressure. They found a large number of cracks around the drill hole during the experiments and presented deformation laws of the rock and boreholes as functions of temperature and pressure while noting that the critical conditions for drilling instability are $500^{\circ} \mathrm{C}$ and $150 \mathrm{MPa}$ of hydrostatic pressure. Kumari et al. [25] studied the effect of reservoir depth, temperature, and sample heterogeneity during hydraulic fracturing and the influences of rock microstructure on fracture propagation. Zhou et al. [26] conducted a hydraulic fracturing experiment under high temperature and pressure with large samples and found that the mechanism for decreased crack initiation pressure is the thermal shock generated by the action of fracturing fluid of rock at high temperature. Brudy and Zoback [27] studied the failure of boreholes in two geothermal projects in Kontinentales Tiefbohrprogramm der Bundesrepublik (KTB) in Germany and Soultz in France. The research indicated that cold mud circulation during the drilling pro- cess leads to a cooling contraction of the rock surrounding the borehole, and the resulting thermal stresses induce tensile cracks. Cornet et al. [28] conducted large-scale water injection experiments in a geothermal reservoir at a $5000 \mathrm{~m}$ depth in Soultz. The test results and borehole images showed that when the pore pressure increases by more than $10 \%$ of the minimum principal stress, massive shear failure can occur in the injection wells and reservoirs.

The above research describes drilling failure during the development of typical HDR geothermal resources around the world and introduces the results of drilling, hydraulic fracturing, and borehole stability under triaxial stresses $\left(\sigma_{1}>\sigma_{2}=\sigma_{3}\right)$ in the laboratory. However, horizontal ground stress inequalities $\left(\sigma_{2} \neq \sigma_{3}\right)$ have a significant influence on borehole failure for the high-temperature rock mass. Owing to limitations in experimental equipment, laboratory studies on borehole failure under high temperatures and true triaxial stresses $\left(\sigma_{1}>\sigma_{2}>\sigma_{3}\right)$ have been rarely reported.

This work used the "true triaxial heat injection rock mechanics experimental system" developed by the Taiyuan University of Technology to perform destruction tests on a borehole under true triaxial stress $\left(\sigma_{1}=4.5 \mathrm{MPa}, \sigma_{2}=1.0\right.$ $\mathrm{MPa}$, and $\sigma_{3}=0.5 \mathrm{MPa}$ ) when a superheated, $500^{\circ} \mathrm{C}$, hightemperature steam is injected. The failure law and drilling morphology under the effect of solid-flow-heat coupling were analyzed to further study the failure mechanism of production wells for HDR geothermal energy extraction. The study showed how thermal cracks and fractures initiate and propagate in borehole surrounding rock under thermohydro-mechanical coupling. The results of this work can be applied to study hydraulic fracture propagation in geothermal reservoirs, and it is useful to assess the stability of borehole surrounding rock in HDR geothermal resource extraction.

\section{Materials and Methods}

2.1. Experimental Equipment. The true triaxial heat injection rock mechanics experimental system (shown in Figure 1) consists of a high-temperature steam generation system, true triaxial pressure equipment, and a testing system. The hightemperature superheated steam is produced from a gas boiler, where the maximum operating temperature and the highest steam pressure are $600^{\circ} \mathrm{C}$ and $3 \mathrm{MPa}$, respectively. The true triaxial pressure equipment has a maximum axial load of 100 tons and a maximum lateral load of 60 tons. An acoustic emission (AE) measurement system (DISP-PCI2, Physical Acoustics Corporation (PAC)) was used to record all emissions generated during the destruction tests for the granite samples. A dial gauge was used to test the deformation of the sample.

2.2. Samples. The samples were made with Shandong grey granite from Pingyi, Shandong province, China, and were in a natural water state with a density of $2.71 \mathrm{~g} / \mathrm{cm}^{3}$, sized at $300 \times 300 \times 300 \mathrm{~mm}$. A hole (diameter $\varphi=20 \mathrm{~mm}$, height $h$ $=180 \mathrm{~mm}$ ) was drilled at the center of each sample, as shown in Figure 2(a). The uniaxial compressive strength of the Shandong grey granite was $130.5 \mathrm{MPa}$, and the single axial 


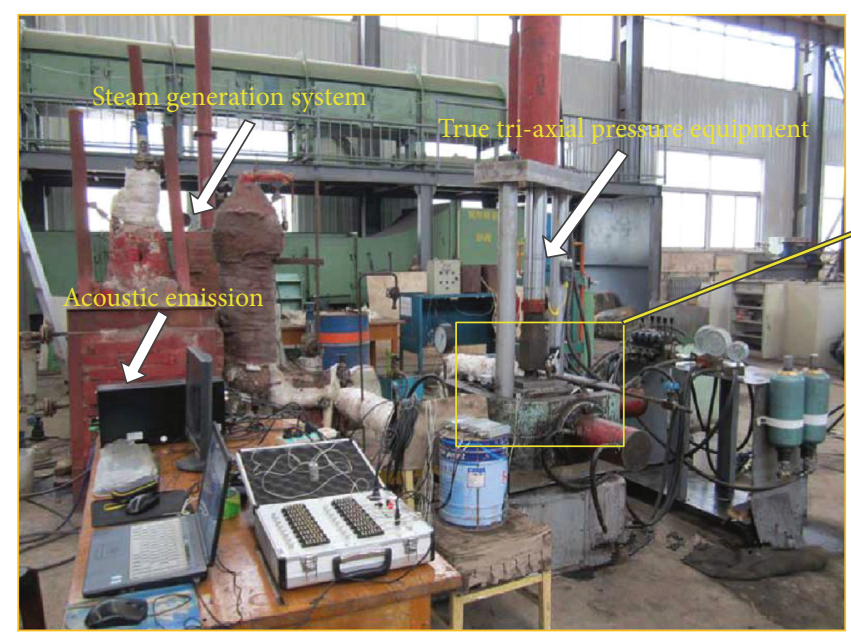

(a)

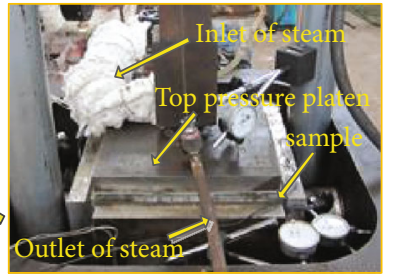

(b)

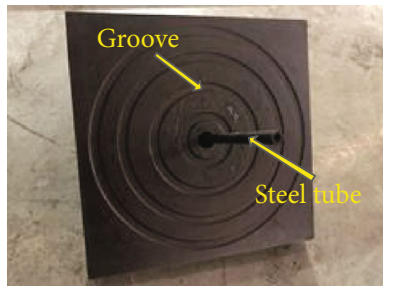

(c)

FIGURE 1: Experimental equipment: (a) true triaxial heat injection rock mechanics experimental system; (b) sample; (c) top pressure platen.

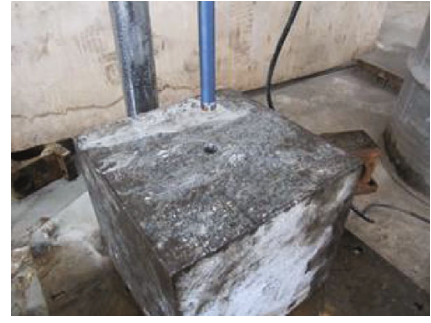

(a)

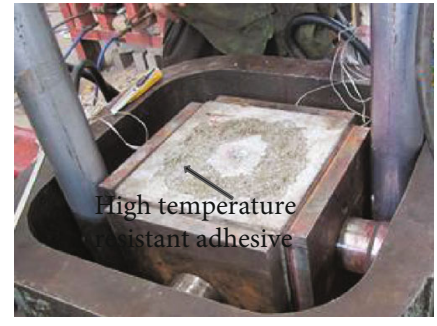

(b)

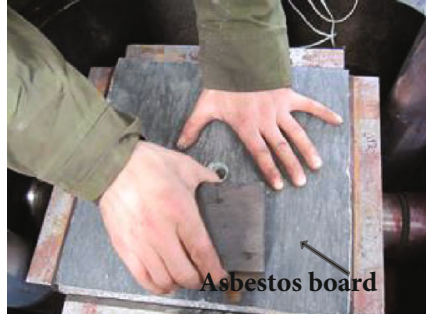

(c)

FIgURE 2: Granite sample: (a) drilling in the sample center; (b) application of the high-temperature-resistant adhesive to the samples; (c) fix the asbestos board to the samples with the high-temperature-resistant adhesive.

TABLe 1: The mineralogical compositions of Luhui granite.

\begin{tabular}{lcccc}
\hline $\begin{array}{l}\text { Mineral } \\
\text { compositions }\end{array}$ & Plagioclase & $\begin{array}{c}\text { Potassium } \\
\text { feldspar }\end{array}$ & Quartz & Biotite \\
\hline Proportion & $40-45 \%$ & $35-40 \%$ & $\begin{array}{c}20- \\
25 \%\end{array}$ & $2-5 \%$ \\
\hline
\end{tabular}

tensile strength was 10.4 MPa. The mineral compositions of the material are shown in Table 1.

2.3. Experiment Procedures. Zhao et al. $[16,24]$ reported that the critical conditions for drilling instability are $500^{\circ} \mathrm{C}$ and $150 \mathrm{MPa}$ of hydrostatic pressure. Thermal cracking mainly occurs at grain boundaries as intergranular microcracks along with apparent weaknesses that develop with rising temperatures. Intragranular cracks are observed when heating to $500^{\circ} \mathrm{C}$, indicating that thermal cracking in granite under high temperature and pressure is induced by both the intragranular and intergranular thermal stresses. Therefore, the superheated steam injected into the sample for the experiment was at $500^{\circ} \mathrm{C}$.

The specific loading methods are shown in Figure 3. Sensors that monitor the steam temperature and pressure were placed at the inlet. Technology utilizing AE was employed to monitor thermal cracking with four $\mathrm{AE}$ sensors placed on the four sides of the samples (Figure 3). Four holes were machined in the four-side pressure platen to ensure the $\mathrm{AE}$ sensors were in direct contact with the rock sample. Environmental noise (generated by the operation of the gas boiler and pressure equipment) was tested before the experiment. The AE-measured amplitude of the noise was between 20 and $40 \mathrm{~dB}$. Therefore, the threshold value of the $\mathrm{AE}$ was $45 \mathrm{~dB}$, the preamplifier gain was set to $40 \mathrm{~dB}$, and the sampling rate was 5 MSPS (mega samples per second, 5 MSPS $=5 \mathrm{MHz}$ ).

Superheated steam at $500^{\circ} \mathrm{C}$ and $2.8 \mathrm{MPa}$ was injected into and flowed through the borehole. To ensure constant steam pressure, a counterbalance valve was assembled at the end of the outlet. The superheated steam was first injected into the borehole via the inlet and then flowed directly into the bottom of the borehole via a steel tube to ensure there was no water in the borehole. The superheated steam flowed out of the borehole via the outlet after heating the surrounding rock, as shown in Figure 3.

An asbestos board and a high-temperature-resistant adhesive were used to seal the injection well during the experiments. The asbestos board was fixed on the samples with a high-temperature-resistant adhesive (see Figure 2) to ensure there was no steam leakage between the sample and the asbestos board. Several grooves were machined on top of the pressure platen (see Figure 1(c)) to ensure there was no 


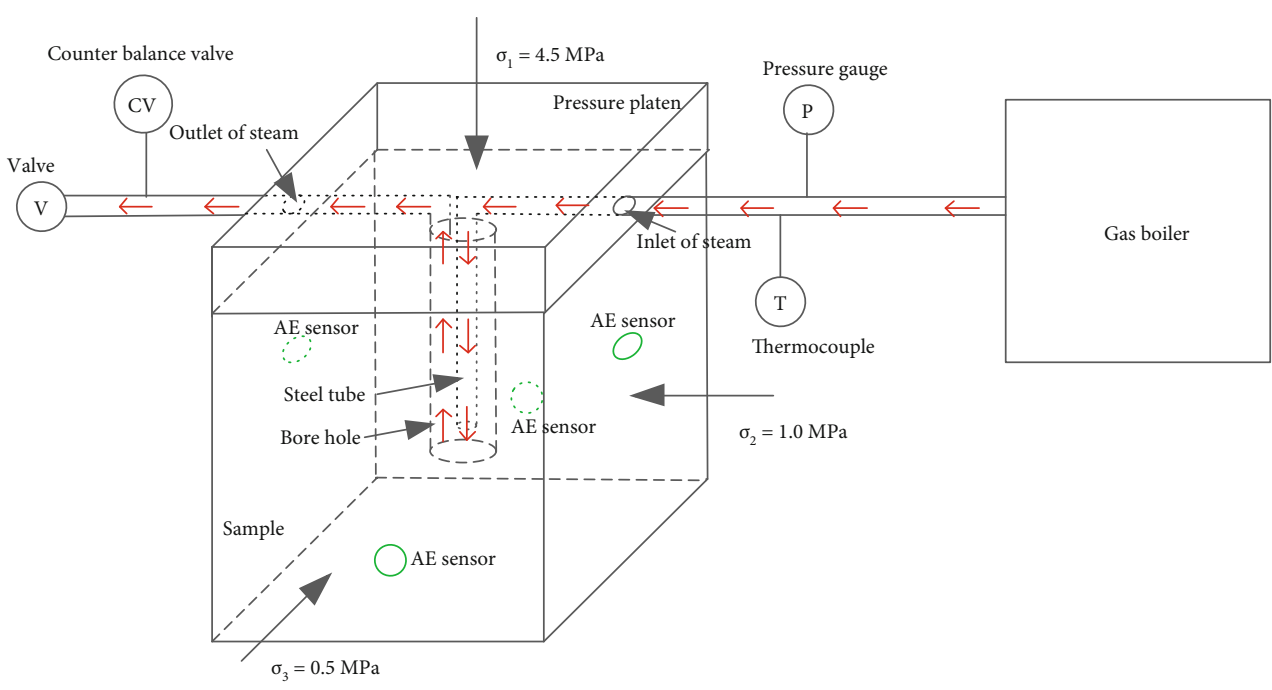

FIgURE 3: Schematic diagram of the experimental setup.

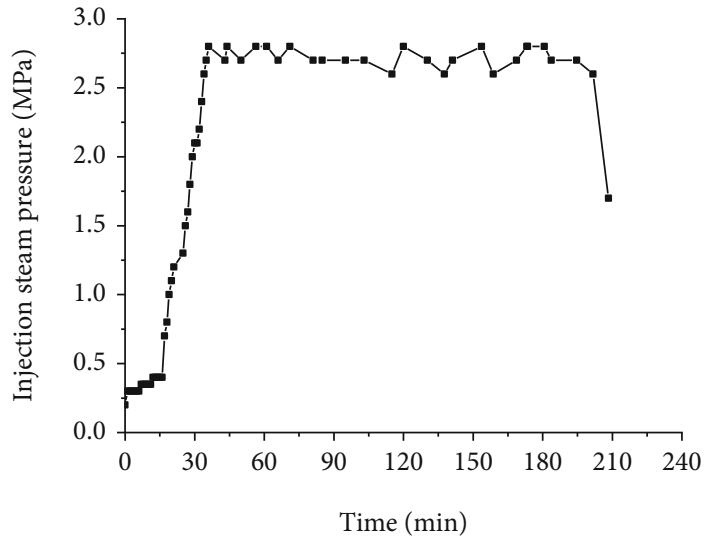

FIGURE 4: Injection steam pressure-time curve.

steam leakage between the asbestos board and the pressure platen under axial pressure.

\section{Results}

3.1. Sample Destruction. Figure 4 shows the experimental pressure-time curve. The experiment lasted $210 \mathrm{~min}$. The superheated steam at $500^{\circ} \mathrm{C}$ was first introduced into the borehole while the pressure was increased at a slow rate of $0.08 \mathrm{MPa} / \mathrm{min}$. The pressure reached its nominal value of $2.8 \mathrm{MPa}$ after $36 \mathrm{~min}$. During this process, the sample did not undergo macroscopic damage. Subsequently, the sample was macroscopically destroyed after approximately $200 \mathrm{~min}$ with constant steam pressure of $2.8 \mathrm{MPa}$ while the steam leaked from the side of the sample.

Figure 5 demonstrates the spatial pattern of the fracture propagation in the sample. Several fractures appeared during the fracture initiation period; these were all vertical fractures. Three of them penetrated the sample, and one changed direction and stopped after extending for a distance. Wing-A was initiated along the direction of the minimum horizontal principal stress. During the expansion process, Wing-A gradually deflected towards the maximum horizontal principal stress. The fractures then propagated to the side and bottom of the sample (Figure 5). Wing-B was initiated at 30 degrees from the maximum horizontal principal stress and gradually turned towards the maximum horizontal principal stress before going through the sample. Wing- $\mathrm{C}$ was initiated and extended along the maximum horizontal main stress direction and also went through the sample. Wing-B and Wing-C only penetrated the side of the sample, and there was no fracture at the bottom. The expansion of the Wing-A, Wing-B, and Wing-C fractures along the height direction $(300 \mathrm{~mm})$ was much larger than the depth of the hole $(180 \mathrm{~mm})$. Wing-D stopped expanding relatively quickly after fracture initiation. Wing-C is a typical tensile crack, while the appearances of Wing- $A$, Wing-B, and Wing-D are the results of the joint action of shear and tension.

There were several bifurcations in the fractures around the wellbore, especially for Fracture A (see Figure 5), which extends along the direction of the minimum horizontal principal stress. Figure 6 shows magnified views of the bifurcations, which are located on the side of the sample, as seen in Figure 5. Tomac and Gutierrez [29] have shown that when the brittle rock is in the solid-fluid-thermal coupled field and convective heat transfer is considered, secondary cracks occur along the main fracture, and the low-viscosity fracturing fluid is more likely to cause additional finger-like cracks to appear near the main fracture. High-temperature superheated steam has lower viscosity than water, and convective heat transfer occurs during the experiments. The hightemperature steam is a fracturing medium and the main reason for the frequent crack bifurcations. In the fracture initiation stage (Stage I of Fractures A, B, and D, as seen in Figure 5), the extension direction of the fractures is affected less by the horizontal principal stress. In the later stage of the expansion (Stage II of Fractures A and B, as seen in Figure 5), the fractures are deflected towards the maximum horizontal principal stress due to the influence of the horizontal principal stress. The thermal stress caused by high temperatures is the main reason for the complicated fracture 


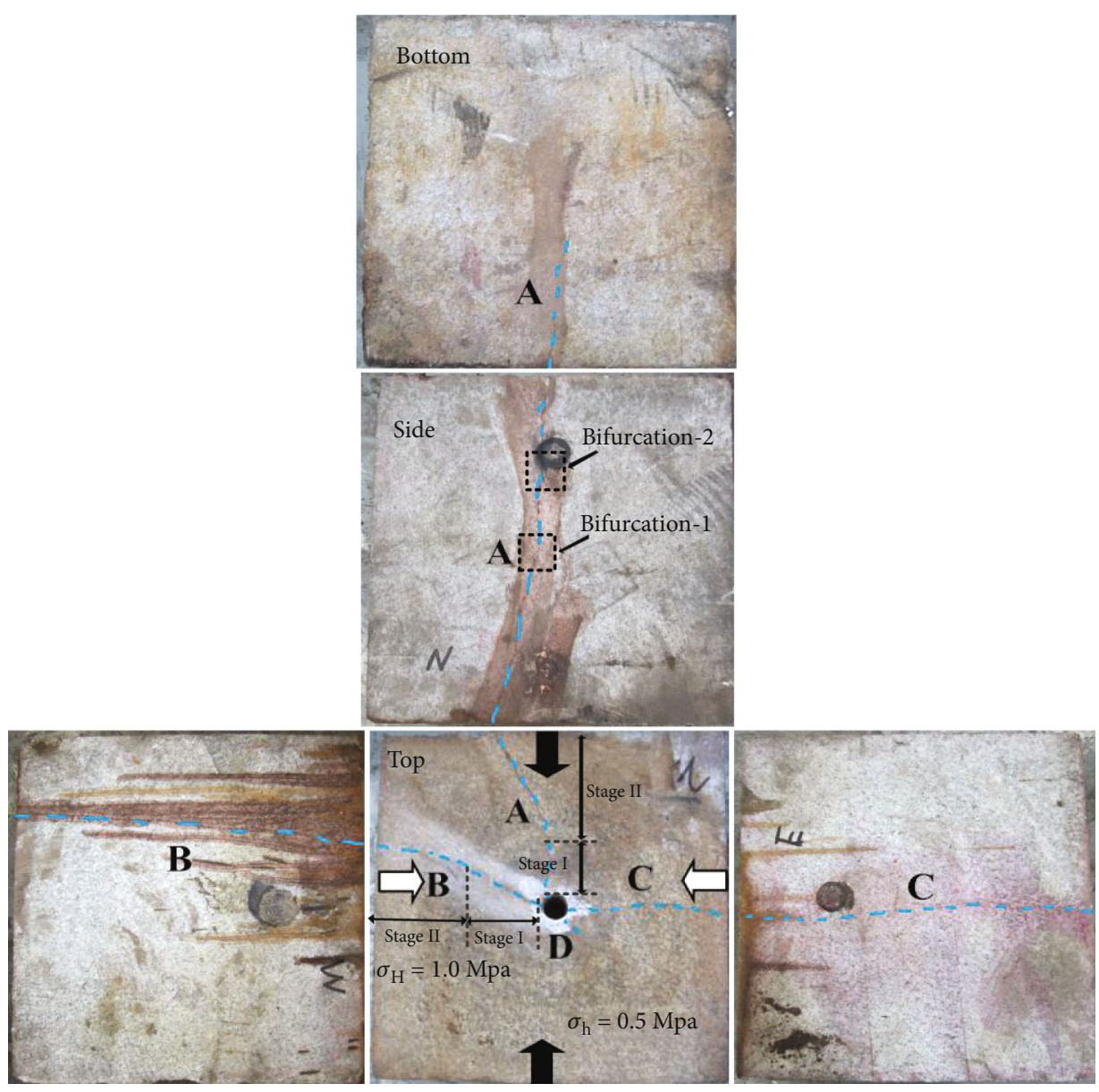

Figure 5: Spatial pattern of the fracture propagation.

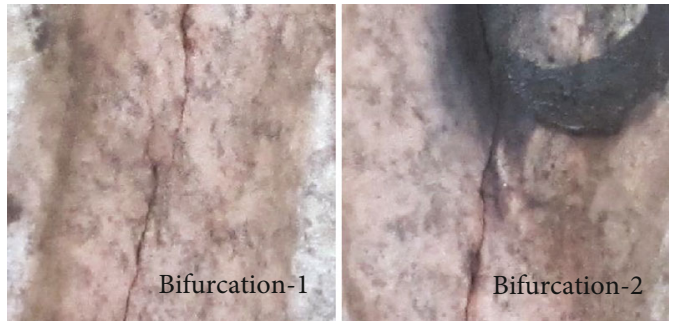

Figure 6: Bifurcations in the cracks.

geometry, which manifests in the form of multiple fractures. The cracks in a rock mass typically reduce the overall mechanical behaviors of the rock mass [30, 31].

3.2. Deformation. Figure 7 indicates the deformation of the sample; the superheated steam pressure in the hole increases from 0 to $2.8 \mathrm{MPa}$ ( 0 to $33 \mathrm{~min}$ ). The axial deformation is compression deformation, and the lateral deformation is expansion deformation. The axial compression deformation rate decreases with the increase of pressure, and the lateral expansion deformation rate increases with pressure. After constant steam pressure of $2.8 \mathrm{MPa}$ from 33 to 108 minutes, the lateral deformation continues to climb, and the deformation is basically linear with time. The axial deformation gradually transforms from the form of compression to that of

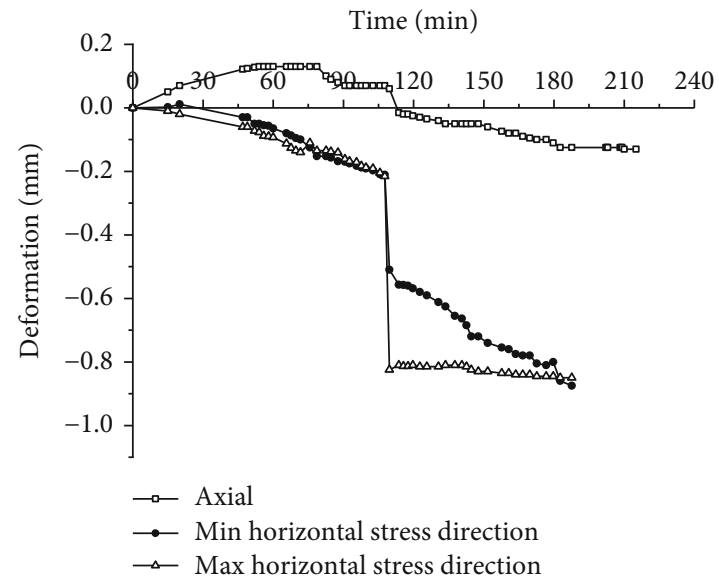

Figure 7: Deformation of the sample.

expansion. At about $108-110 \mathrm{~min}$, the $0.3 \mathrm{~mm}$ expansion occurs in the direction of the lateral maximum horizontal principal stress in 2 minutes, and $0.6 \mathrm{~mm}$ expansion appears in the lateral minimum horizontal principal stress in the same period. From 110 to 200 minutes, the specimen keeps expanding, the lateral deformation rate becomes stable, and the axial deformation rate gradually decreases until the specimen is destroyed. 


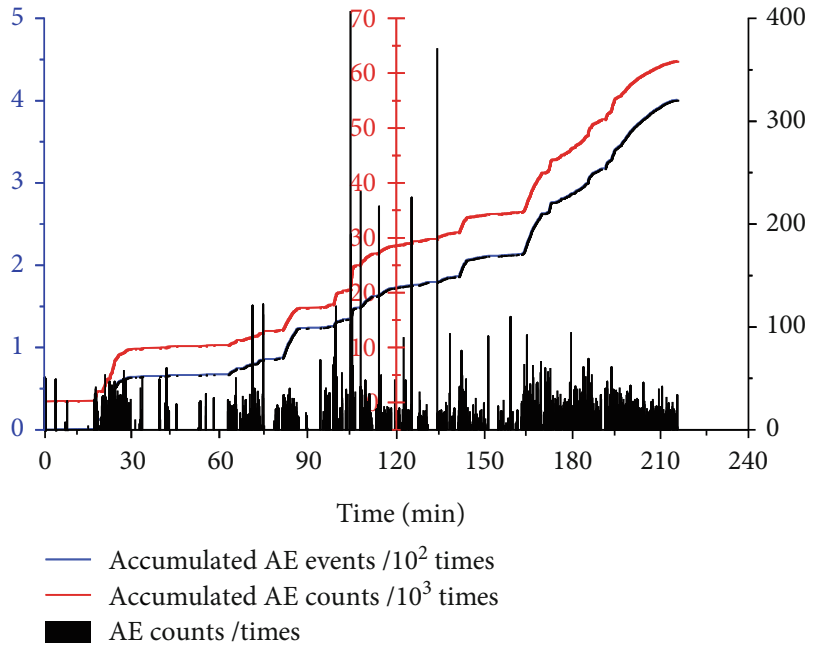

(a)

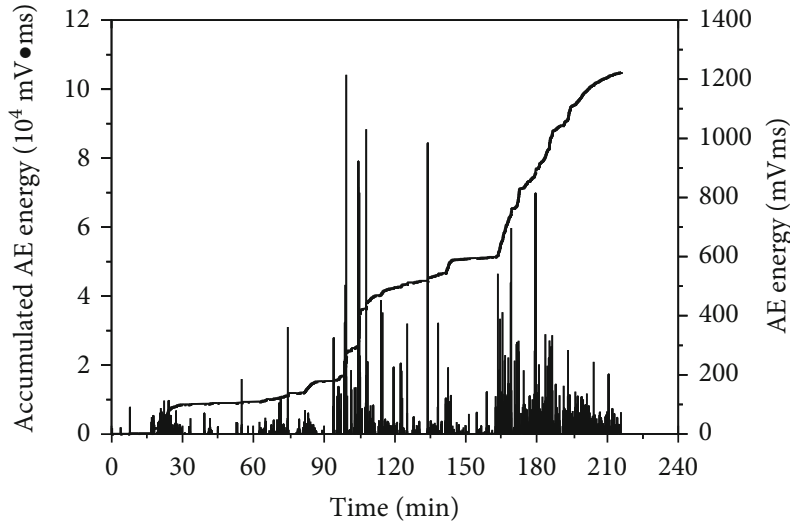

(b)

FIgURE 8: Variation in the AE energy with time.

3.3. Acoustic Emission Feature. When the mineral particles in the rock are shifted or microcracking occurs, the strain energy is released in the form of elastic waves, which cause AE events. During the loading process, each AE event corresponds to the occurrence of a microfracture within the rock; hence, there is a corresponding relationship between the $\mathrm{AE}$ event and the fracture expansion $[32,33]$.

The AE energy reflects the energy level of the stress waves produced by crack propagation, which characterizes the crack propagation activity within the rock samples. The accumulated energy of the AE events reflects the energy necessary to cause crack initiation and extension. The AE event and count reflect the frequency of microcracking.

Figure 8 shows variations in the $\mathrm{AE}$ event, count, and energy that were collected during the experiment. The AE count and energy were low from 0 to $100 \mathrm{~min}$, and an interval between the quiet zone and the concentrated area appeared at this time. Thus, the accumulated count and energy of the AE increased slowly. The AE count and energy were high from 100 to $110 \mathrm{~min}$, and the accumulated event, count, and energy of the AE increased rapidly. From 110 to $160 \mathrm{~min}$, the AE count and energy slightly reduced but were still higher than at the initial stage of the experiment, which caused the accumulated event, count, and energy to increase more slowly. After $160 \mathrm{~min}$, a second AE concentration area appeared, and the cumulative parameters increased rapidly until the sample was destroyed.

From 100 to $110 \mathrm{~min}$, the $\mathrm{AE}$ event, count, and energy increased rapidly. At this point, the sample did not experience macroscopic damage, and there was a substantial increase in the intensity and the frequency of AE signals. This indicates that the fracture initiation occurred around the borehole of the sample.

\section{Discussion}

4.1. Macrocrack Initiation. In Figure 8, from 100 to 110 minutes, the occurrence of AE count and energy increased, the accumulated event, count, and energy of the AE increased rapidly. These AE activities are believed to be an indication of hydraulic fracture initiation [30]. From Figure 7, it can be seen that at $108-110 \mathrm{~min}, 0.3 \mathrm{~mm}$ expansion deformation occurs in the direction of the lateral maximum principal stress of the rock, and $0.6 \mathrm{~mm}$ expansion deformation takes place in the direction of the lateral minimum horizontal principal stress. The results of deformation and AE in the experiment indicate that large-scale destruction occurred within the sample during 100-110 min. The initiation of crack happens, and macrocrack initiation develops.

AE localization events are microcrack damages monitored in real time. They can reflect the accumulation of microfaults and the evolution of macrocrack formation. Deformation can only reflect the results of the macrocrack development of the specimen but cannot reflect the process of accumulation of microfaults. The judgment of the moment of the macrocrack initiation by the deformation is delayed compared with one of the acoustic emission characteristic parameters. Hence, AE technology is an effective method to predict fracture initiation.

4.2. Destruction Rules of the Borehole. The AE event locations recorded during the experiments were used to estimate the fracture propagation in the rock surrounding the borehole. The fundamental basis for calculating the location is the simple time-distance relationship as implied from the velocity of the sound wave.

Figure 9 shows the AE location map for the destruction, which reflects the fracture law of the sample at different experimental stages. The acoustic locations obtained at the different stages are indicated by different colors. Figure 9(a) shows the surface morphology of the sample after failure, Figures 9(c)-9(f) indicate the thermal crack locations around the borehole before fracture initiation, and Figures 9 (b) and $9(\mathrm{~g})-9(\mathrm{n})$ demonstrate the location of the AE during the period from fracture initiation to macroscopic failure. The maximum experimental steam pressure was $2.8 \mathrm{MPa}$, which 


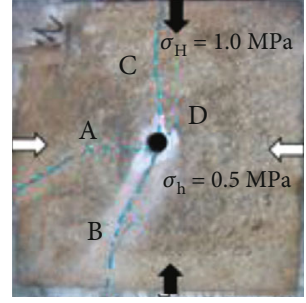

(a)

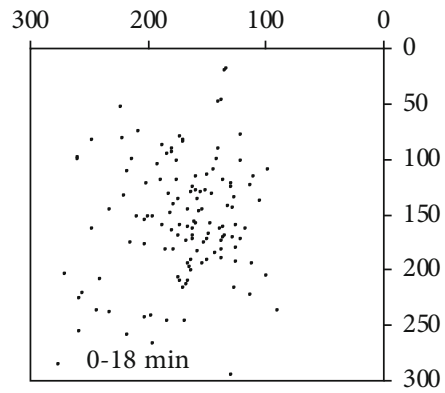

(c)

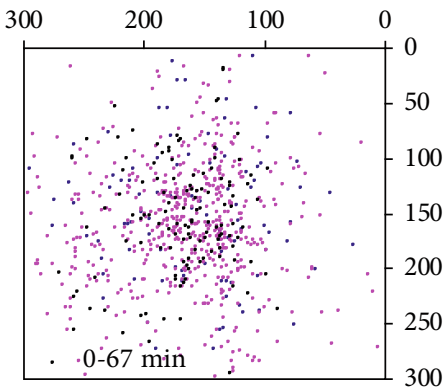

(e)

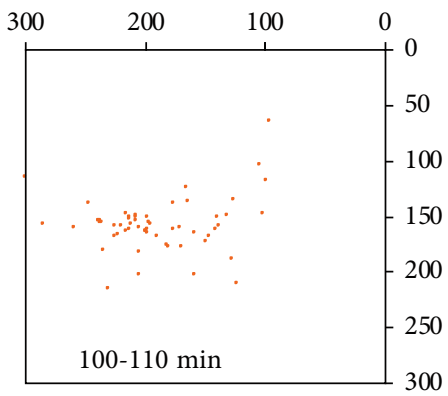

(g)

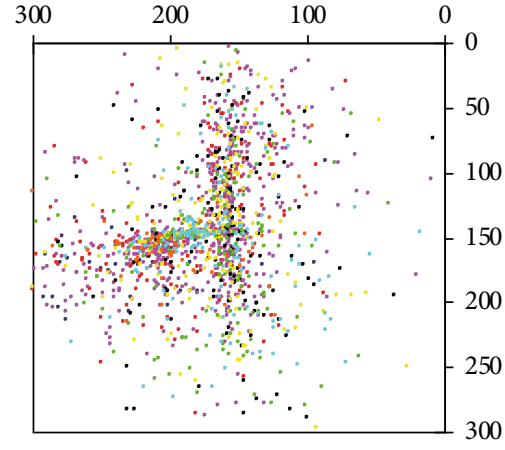

(b)

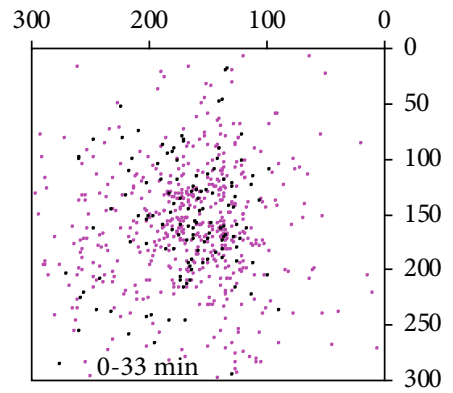

(d)

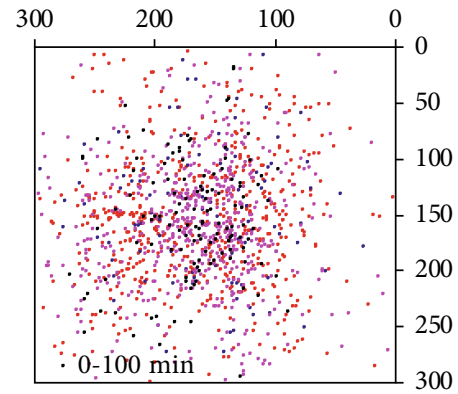

(f)

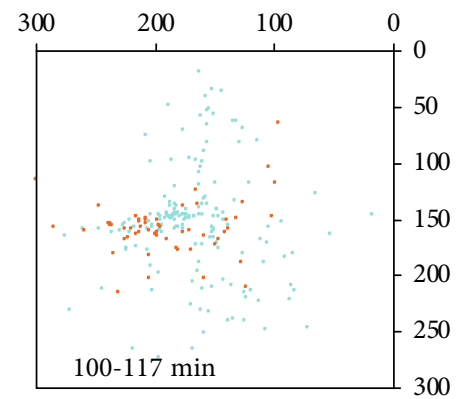

(h)

Figure 9: Continued. 


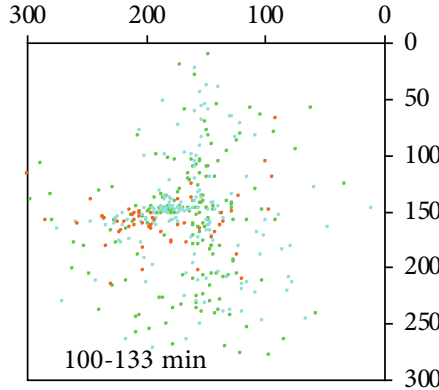

(i)

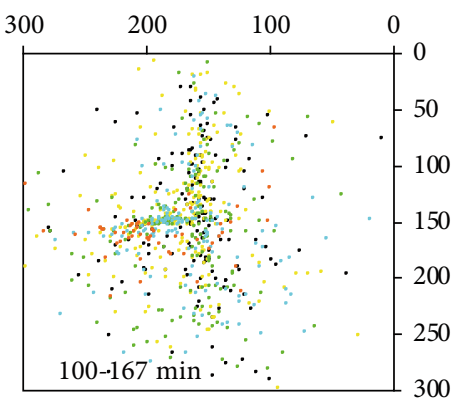

(k)

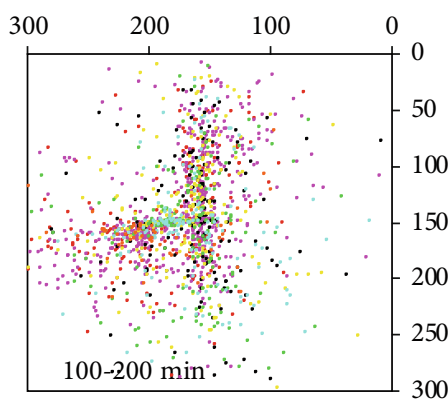

(m)

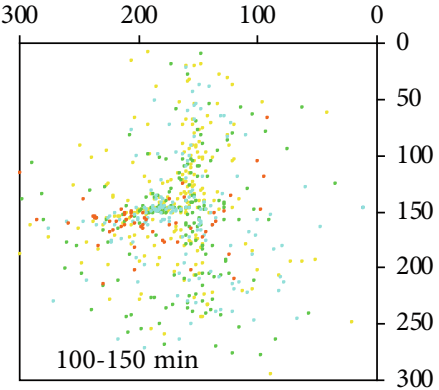

(j)

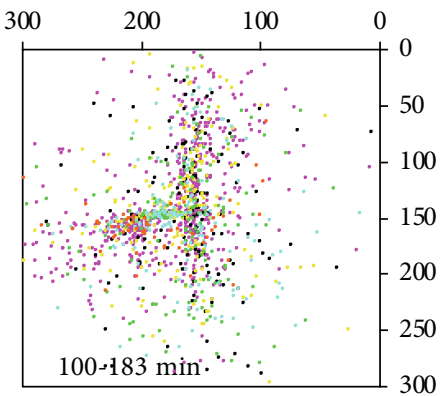

(l)

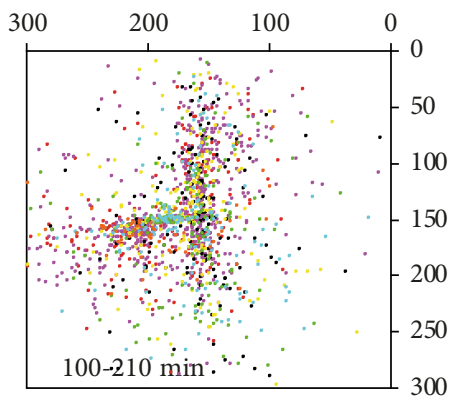

(n)

FIGURE 9: AE location map at different stages: (a) macroscopic failure of the sample; (b) AE location after failure; (c) AE location at 0-18 min in the thermal cracking stage; (d) AE location at 0-33 min in the thermal cracking stage; (e) AE location at 0-67 min in the thermal cracking stage; (f) AE location at 0-100 min in the thermal cracking stage; (g) AE location at 100-110 min in the fracture initiation stage; (h) AE location at 100-117 min in the fracture propagation stage; (i) AE location at 100-133 min in the fracture propagation stage; (j) AE location at 100-150 $\mathrm{min}$ in the fracture propagation stage; (k) AE location at 100-167 min in the fracture propagation stage; (l) AE location at 100$183 \mathrm{~min}$ in the fracture propagation stage; $(\mathrm{m})$ AE location at 100-200 $\mathrm{min}$ in the fracture propagation stage; (n) AE location at 100$210 \mathrm{~min}$ in the fracture propagation stage.

is far below the tensile strength $(10.4 \mathrm{MPa})$ of granite. The sample was destroyed after 200 min under constant pressure $(2.8 \mathrm{MPa})$ during the experiment.

The destruction of rock that surrounds boreholes can be divided into three stages.

4.2.1. Thermal Cracking Stage. The high-temperature superheated steam flow causes thermal stresses in the surrounding rock of a borehole, which induces thermal cracking, but is insufficient to form macroscopic fractures. At this stage, the main factor impacting the thermal cracking of the sample is the thermal stress caused by the high-temperature superheated steam flowing in the borehole, while the triaxial stress is the secondary factor. Figures 9(c) and 9(d) show the thermal crack AE location events as the steam pressure increased from 0 to $2.8 \mathrm{MPa}(0-33 \mathrm{~min})$ in the borehole, and Figures 9(e) and 9(f) show the $\mathrm{AE}$ events during the constant pressure process (33-100 min). The thermal cracks were randomly distributed around the borehole and gradually expanded outwards with the borehole at the center. During this process, the density of the thermal cracks around the borehole gradually increased.

As can be seen from Figure 8, the AE energy of the thermal cracking is lower than those during fracture propagation, while the quiet section and the dense section of the AE events appeared alternatively. Thermal cracking is the result of the alternating accumulation and release of energy as generated by the deformation mismatch between grains with different thermal expansivities. The thermal cracking of granite occurs mainly at grain boundaries, while cracks in the grains occur 
when the granite is heated to $500^{\circ} \mathrm{C}[15,16]$. A large number of thermal cracks occurred around the borehole, and the accumulation of these microcracks promotes the formation of the initial fracture.

4.2.2. Fracture Initiation Stage. Figure $9(\mathrm{~g})$ indicates the location of the AE during the fracture initiation stage (100$110 \mathrm{~min}$ ). After the thermal cracking stage, the density of thermal cracks around the borehole increased, and microcracks connected to each other and expanded to form the initial fracture. As seen in Figure 8, the energy of the AE was large at this stage, and the cumulative parameters increased rapidly. The location of the fracture initiation was random and nearly independent of the ground stress. There were four initial fractures randomly distributed around the borehole, as seen in Figure 6. Theoretically, initial fractures should be initiated along the maximum horizontal principal stress (e.g., Fracture $\mathrm{C}$ in Figure 5), but Fractures $\mathrm{A}, \mathrm{B}$, and $\mathrm{D}$ (in Figure 5) violated the above law.

Under thermo-hydro-mechanical coupling, propagation of macrocracks was affected by the combined effects of the horizontal principal stress, the existing thermal cracks, and the shape of mineral grains. At a temperature above $300^{\circ} \mathrm{C}$, a macrocrack was formed by connecting the thermal cracks during its propagation [34]. Moreover, thermal fractures allow the steam at high pressure to penetrate into and cause stress concentration around the fracture tips, potentially pushing the thermal fractures to propagate further [35]. There were large thermal cracks around the borehole, as shown in Figure 9. Hence, the randomness of the spatial distribution for thermal cracking is favorable to the formation of multiple weak sections around the borehole. This easily forms multiple initial fractures that are barely affected by the horizontal principal stress.

4.2.3. Fracture Propagation Stage. Figures 9(g)-9(n) show the time-order characteristics of the AE localization events during fracture propagation $(110-210 \mathrm{~min})$ in the sample. The $\mathrm{AE}$ events were densely distributed around the borehole and along the fracture direction. Fracture A, which is in the direction of the minimum horizontal principal stress, was formed earlier (Figure 9(g)), and Fractures B and C, which are in the direction of the maximum horizontal principal stress, appeared soon after (Figures $9(\mathrm{~h})-9(\mathrm{j})$ ). Due to the small size of Fracture D, the AE location is unknown. In the initial fracture propagation stage, the extension direction of the fractures was affected less by the horizontal principal stress. In the later stage of fracture expansion, the fractures deflected towards the maximum horizontal principal stress due to the influence of the horizontal principal stress.

The time-order characteristics of the AE localization events in Figures 9(h)-9(j) indicate that Fracture A underwent a process of expansion, crack arrest, and reexpansion. When Fracture A was experiencing crack arrest, initial fractures were formed for Fractures B and C, and three cracks expanded together thereafter (133-223 min). Crack expansion always occurs along the easiest direction. The intermittent expansion of Fracture A indicates that the energy for cracking is insufficient, and the maximum horizontal princi- pal stress cannot be overcome. Therefore, the energy needs to be accumulated.

The thermal cracking is favorable to form multiple initial fractures around the borehole, which are barely affected by the horizontal principal stress (seen in Figure 6). The hightemperature effect (thermal stress) is the main reason for the complexity in the fracture geometry for the sample, which manifests itself as the failure mode for multiple fractures.

4.3. Extension Resistance of Crack Propagation. Figure 5 shows that Fracture D stopped expanding shortly after fracture initiation, and Figures 9(h)-9(j) demonstrate that Fracture A intermittently extended. Figure 6 show that the fractures (especially Fracture A) bifurcated during the expansion, which suggests that the extension resistance is relatively large during fracture propagation. Temperature stresses and pore pressures cannot continuously provide the energy for fractures to expand indefinitely. In particular, Fracture A began cracking along the direction of the minimum horizontal principal stress and needed to overcome the constraints of the stress to continue expanding. This requires the accumulation of energy or an expansion in the direction of smaller energy consumption (crack bifurcation).

The multicrack propagation mode and the phase transition of the high-temperature steam during crack propagation are the main reasons for the increased extension resistance. During crack propagation, the high-temperature steam at the crack tip turned into water due to heat transfer. This caused reduced thermal stress and pressure within the fracture, and the added resistance inhibited the crack from expanding. Simultaneously, the high-temperature vapor has low viscosity, which makes it easier to penetrate into the rock, and increases thermal damage around the crack, which reduces the pressure in the crack and delays its initiation and expansion [29].

4.4. Influence of Thermal Stress on the Destruction of the Rock Surrounding the Wellbore in HDR Geothermal Energy Recovery. Thermal stresses can cause damage to rocks. The rock surrounding the production well is destroyed by rising temperatures (high-temperature steam passes through the ambient temperature rock mass), which damages the injection well due to cooling (ambient temperature water is injected into the high-temperature rock mass). Based on the experimental results, while a production well is in operation, the surrounding rock primarily undergoes expansion deformations, as shown in Figure 7. The failure is mainly due to the cracking of the rock that surrounds the wellbore and from the extension of these cracks as there is no significant contraction and collapse of the borehole (seen in Figure 5). Expansion deformations of the rock mass cause permeability [36], and the efficiency of geothermal energy extraction in an HDR reduced.

Thermal cracking during the cooling process is more severe than that during the heating process [22]. According to the theory of thermoelasticity, localized tensile thermal stresses are more likely to occur near the wellbore of the injection well, while failure of the injection wellbore is more 
severe than that of the production wellbore, which results in greater crack widths [29]. In addition, the large temperature difference between the injected fluid and the rock body results in the complex thermo-fluid-solid coupling effect between rock and liquid, which causes intense thermal shock to the rock body $[26,37]$. Thermal shock causes elastic wave shock and thermal wave shock near the borehole, and the tensile stress caused by these two shocks makes it easier for the borehole to fracture [26]. Research has shown that the subcritical crack growth velocity of rock in water or an aqueous solution is much higher than that in air, and the fracture toughness of rock decreases when the experimental environment was changed from air condition to water condition [38]. Large shear failures of injection wells and reservoirs occur when a large amount of water is injected in the $5000 \mathrm{~m}$ deep experimental geothermal reservoir at Soultz (France) [28]. Therefore, the destruction of the injection well is more severe than that of the production well and has a more complex destruction pattern. Large-scale shear damage in the reservoir is beneficial to increase the permeability [39] and heat transfer area and improve the efficiency of geothermal energy extraction in an HDR.

When the surrounding rock of the injection well is broken, the water exits at the back of the fracture tip and changes into steam at the tip. The water pushes the steam and expands the fracture. The large compressibility of the steam indicates that crack expansion can cause an instantaneous expansion of the steam, which has a dynamic effect on fracture propagation to induce larger fracture openings. For example, the use of supercritical carbon dioxide for HDR reservoir fracturing takes advantage of thermal effects and the instantaneous expansion of gas during crack propagation, which forms fractures with larger widths that enhance the reservoir permeability. In contrast, when the surrounding rock of a production well is broken, the steam exits at the back of the fracture tip and changes into water at the tip. When the crack expands instantaneously, the vapor liquefies, pore pressure in the fracture decreases, and energy accumulation is needed to continue the crack expansion. When the extension resistance increases, the cracks either stop or intermittently expand. The viscosity of injected fluid plays an important role in determining the crack expansion effect $[25,29,40]$. Superheated steam in the fracture tip induces faster crack expansion in HDR reservoirs than water in the fracture tip because of the high mobility of steam.

\section{Conclusions}

This study used the "true triaxial heat injection rock mechanics experimental system" to destroy a borehole under triaxial stresses under the injection of high-pressure $(2.8 \mathrm{MPa})$ and high-temperature $\left(500^{\circ} \mathrm{C}\right)$ superheated steam. The following conclusions are drawn from the experiments:

(1) The effect of thermal stresses causes thermal cracking to be randomly distributed around the borehole, which gradually expands outwards with the borehole as the center. This leads to the appearance of fracture characteristics around the borehole, where the orien- tation of the fracture initiation is barely constrained by the geostress. In the fracture propagation process, the direction of crack expansion is affected by the ground stress and gradually deflects along the direction of the maximum horizontal principal stress

(2) During the fracture expansion process, along the direction of the maximum nonhorizontal principal stress, the extension resistance is large, cracks are arrested, and intermittent expansion occurs. This is primarily because the high-temperature vapor has low viscosity and can easily penetrate the cracks and liquefy at the tips

(3) The destruction of rock that surrounds the borehole can be divided into three stages: (a) thermal cracking, (b) fracture initiation, and (c) fracture propagation. AE technology is an effective method to estimate the fracture initiation and propagation

\section{Data Availability}

All data used to support the study is included within the article.

\section{Conflicts of Interest}

The authors declare that there is no conflict of interest regarding the publication of this paper.

\section{Acknowledgments}

This work was supported by the National Natural Science Foundation of China (Nos. 51504220, U1810104, and 51404161) and the National Science Foundation of Shanxi Province (No. 201901D111142).

\section{References}

[1] K. Breede, K. Dzebisashvili, X. L. Liu, and G. Falcone, “A systematic review of enhanced (or engineered) geothermal systems: past, present and future," Geothermal Energy, vol. 1, no. 1, p. 4, 2013.

[2] P. Olasolo, M. C. Juárez, M. P. Morales, S. D’Amico, and I. A. Liarte, "Enhanced geothermal systems (EGS): a review," Renewable and Sustainable Energy Reviews, vol. 56, pp. 133144, 2016.

[3] Z. J. Wan, Y. S. Zhao, and J. R. Kang, "Forecast and evaluation of hot dry rock geothermal resource in China," Renewable Energy, vol. 30, no. 12, pp. 1831-1846, 2005.

[4] Y. S. Zhao, Z. J. Feng, B. P. Xi, J. C. Zhao, Z. J. Wan, and A. C. Zhou, "Prospect of HDR geothermal energy exploitation in Yangbajing, Tibet, China, and experimental investigation of granite under high temperature and high pressure," Journal of Rock Mechanics and Geotechnical Engineering, vol. 3, no. 3, pp. 260-269, 2011.

[5] Z. J. Feng, Y. S. Zhao, A. C. Zhou, and N. Zhang, "Development program of hot dry rock geothermal resource in the Yangbajing Basin of China," Renewable Energy, vol. 39, no. 1, pp. 490-495, 2012. 
[6] D. V. Duchane, "Geothermal energy from hot dry rock: a renew able energy technology moving towards practical implementation," Renewable Energy, vol. 9, no. 1-4, pp. 1246-1249, 1996.

[7] S. Kelkar, G. WoldeGabriel, and K. Rehfeldt, "Lessons learned from the pioneering hot dry rock project at Fenton Hill, USA," Geothermics, vol. 63, no. 9, pp. 5-14, 2016.

[8] H. Muraoka, T. Uchida, M. Sasada et al., "Deep geothermal resources survey program: igneous, metamorphic and hydrothermal processes in a well encountering $500^{\circ} \mathrm{C}$ at $3729 \mathrm{~m}$ depth, Kakkonda, Japan," Geothermics, vol. 27, no. 5-6, pp. 507-534, 1998.

[9] A. Genter, K. Evans, N. Cuenot, D. Fritsch, and B. Sanjuan, "Contribution of the exploration of deep crystalline fractured reservoir of Soultz to the knowledge of enhanced geothermal systems (EGS)," Comptes Rendus Geoscience, vol. 342, no. 78, pp. 502-516, 2010.

[10] G. Zimmermann and A. Reinicke, "Hydraulic stimulation of a deep sandstone reservoir to develop an enhanced geothermal system: laboratory and field experiments," Geothermics, vol. 39, no. 1, pp. 70-77, 2010.

[11] M. W. McClure and R. N. Horne, "An investigation of stimulation mechanisms in enhanced geothermal systems," International Journal of Rock Mechanics \& Mining Sciences, vol. 72, pp. 242-260, 2014.

[12] B. F. Ayling, R. A. Hogarth, and P. E. Rose, "Tracer testing at the Habanero EGS site, central Australia," Geothermics, vol. 63, pp. 15-26, 2016.

[13] E. Schill, A. Genter, N. Cuenot, and T. Kohl, "Hydraulic performance history at the Soultz EGS reservoirs from stimulation and long-term circulation tests," Geothermics, vol. 70, pp. 110-124, 2017.

[14] Y. Zhao, P. F. He, Y. F. Zhang, and C. L. Wang, "A new criterion for a toughness-dominated hydraulic fracture crossing a natural frictional interface," Rock Mechanics and Rock Engineering, vol. 52, no. 8, pp. 2617-2629, 2019.

[15] C. David, B. Menendez, and M. Darot, "Influence of stressinduced and thermal cracking on physical properties and microstructure of La Peyratte granite," International Journal of Rock Mechanics and Mining Sciences, vol. 36, no. 4, pp. 433-448, 1999.

[16] Y. S. Zhao, Z. J. Feng, Y. Zhao, and Z. J. Wan, “Experimental investigation on thermal cracking, permeability under HTHP and application for geothermal mining of HDR," Energy, vol. 132, pp. 305-314, 2017.

[17] S. W. Chen, C. H. Yang, and G. B. Wang, "Evolution of thermal damage and permeability of Beishan granite," Applied Thermal Engineering, vol. 110, pp. 1533-1542, 2017.

[18] J. W. Wu, J. W. Gao, Z. J. Feng, S. P. Chen, and T. Y. Nie, "Investigation of fracture process zone properties of mode I fracture in heat-treated granite through digital image correlation," Engineering Fracture Mechanics, vol. 235, article 107192, pp. 1-11, 2020.

[19] T. Berard and F. H. Cornet, "Evidence of thermally induced borehole elongation: a case study at Soultz, France," International Journal of Rock Mechanics and Mining Sciences, vol. 40, no. 7-8, pp. 1121-1140, 2003.

[20] B. Haimson, "Micromechanisms of borehole instability leading to breakouts in rocks," International Journal of Rock Mechanics and Mining Sciences, vol. 44, no. 2, pp. 157-173, 2007.
[21] Y. L. Zhao, Y. X. Wang, W. J. Wang, L. M. Tang, Q. Liu, and G. M. Cheng, "Modeling of rheological fracture behavior of rock cracks subjected to hydraulic pressure and far field stresses," Theoretical and Applied Fracture Mechanics, vol. 101, pp. 5966, 2019.

[22] J. Browning, P. Meredith, and A. Gudmundsson, "Coolingdominated cracking in thermally stressed volcanic rocks," Geophysical Research Letters, vol. 43, pp. 1-9, 2016.

[23] J. C. Zhao, "Experimental research on rock breaking by impacting-cutting drilling under high-temp and high-press condition," Taiyuan University of Technology, Taiyuan, 2010.

[24] Y. S. Zhao, Z. J. Feng, B. P. Xi, Z. J. Wan, D. Yang, and W. G. Liang, "Deformation and instability failure of borehole at high temperature and high pressure in hot dry rock exploitation," Renewable Energy, vol. 77, pp. 159-165, 2015.

[25] W. G. P. Kumari, P. G. Ranjith, M. S. A. Perera et al., "Hydraulic fracturing under high temperature and pressure conditions with micro CT applications: geothermal energy from hot dry rocks," Fuel, vol. 230, pp. 138-154, 2018.

[26] C. B. Zhou, Z. J. Wan, Y. Zhang, and B. Gu, "Experimental study on hydraulic fracturing of granite under thermal shock," Geothermics, vol. 71, pp. 146-155, 2018.

[27] M. Brudy and M. D. Zoback, "Drilling-induced tensile wallfractures: implications for determination of in-situ stress orientation and magnitude," International Journal of Rock Mechanics and Mining Sciences, vol. 36, no. 2, pp. 191-215, 1999.

[28] F. H. Cornet, T. Berard, and S. Bourouis, "How close to failure is a granite rock mass at a $5 \mathrm{~km}$ depth?," International Journal of Rock Mechanics and Mining Sciences, vol. 44, no. 1, pp. 4766, 2007.

[29] I. Tomac and M. Gutierrez, "Coupled hydro-thermomechanical modeling of hydraulic fracturing in quasi-brittle rocks using BPM-DEM," Journal of Rock Mechanics and Geotechnical Engineering, vol. 9, no. 1, pp. 92-104, 2017.

[30] Y. L. Zhao, L. Y. Zhang, W. J. Wang, Q. Liu, L. M. Tang, and G. M. Cheng, "Experimental study on shear behavior and a revised shear strength model for infilled rock joints," International Journal of Geomechanics, vol. 20, no. 9, article 04020141, 2020.

[31] Y. L. Zhao, C. S. Zhang, Y. X. Wang, and H. Lin, "Shear-related roughness classification and strength model of natural rock joint based on fuzzy comprehensive evaluation," International Journal of Rock Mechanics and Mining Sciences, 2020.

[32] S. Yuyama, Z. W. Li, Y. Ito, and M. Arazoe, "Quantitative analysis of fracture process in RC column foundation by moment tensor analysis of acoustic emission," Construction and Building Materials, vol. 13, no. 1-2, pp. 87-97, 1999.

[33] R. B. Mao, Z. J. Feng, Z. H. Liu, and Y. S. Zhao, "Laboratory hydraulic fracturing test on large-scale pre-cracked granite specimens," Journal of Natural Gas Science Engineering, vol. 44, pp. 278-286, 2017.

[34] J. P. Zuo, J. T. Wang, Y. J. Sun, Y. Chen, G. H. Jiang, and Y. H. $\mathrm{Li}$, "Effects of thermal treatment on fracture characteristics of granite from Beishan, a possible high-level radioactive waste disposal site in China," Engineering Fracture Mechanics, vol. 182, pp. 425-437, 2017.

[35] D. T. Ngo and F. L. Pellet, "Numerical modeling of thermallyinduced fractures in a large rock salt mass," Journal of Rock Mechanics and Geotechnical Engineering, vol. 10, no. 5, pp. 844-855, 2018. 
[36] Y. Zhao, C. L. Wang, Y. F. Zhang, and Q. Liu, "Experimental study of adsorption effects on shale permeability," Natural Resources Research, vol. 28, no. 4, pp. 1575-1586, 2019.

[37] R. Y. Yang, Z. W. Huang, Y. Shi, Z. Q. Yang, and P. P. Huang, "Laboratory investigation on cryogenic fracturing of hot dry rock under triaxial-confining stresses," Geothermics, vol. 79, pp. 46-60, 2019.

[38] Y. L. Zhao, L. Y. Zhang, J. Liao, W. J. Wang, Q. Liu, and L. M. Tang, "Experimental study of fracture toughness and subcritical crack growth of three rocks under different environments," International Journal of Geomechanics, vol. 20, no. 8, article 04020128, 2020.

[39] Y. Zhao, C. L. Wang, and J. Bi, "Analysis of fractured rock permeability evolution under unloading conditions by the model of elastoplastic contact between rough surfaces," Rock Mechanics and Rock Engineering, vol. 53, pp. 5795-5808, 2020.

[40] J. Kim and G. J. Moridis, "Numerical analysis of fracture propagation during hydraulic fracturing operations in shale gas systems," International Journal of Rock Mechanics and Mining Sciences, vol. 76, pp. 127-137, 2015. 